15

\title{
Об исследовании полного внешнего отражения рентгеновских лучей от поверхности твердых тел
}

\author{
(C) В.М. Стожаров \\ Российский государственный педагогический университет им. Герцена, \\ 191186 Санкт-Петербург, Россия \\ e-mail: gut1111@yandex.ru
}

(Поступило в Редакцию 8 сентября 2015 г. В окончательной редакции 29 июня 2016 г.)

Проведено комплексное исследование отражения рентгеновских лучей от поверхности твердых тел, включающее измерения с параболическим зеркалом рентгенограмм полного внешнего отражения и дифракции рентгеновских лучей. Разработаны принципы теоретической обработки полученных рентгенограмм. Установлена обратная зависимость показателя преломления рентгеновских лучей от межплоскостных расстояний в кристаллитах.

DOI: 10.21883/JTF.2017.01.44028.1586

\section{Введение}

Полное внешнее отражение (ПВО) рентгеновских лучей от поверхности твердых тел при скользящих углах падения, впервые обнаруженное Комптоном [1] и детально изученное для ряда веществ Линником и Лашкаревым [2], свидетельствует о величине показателя преломления рентгеновских лучей в твердых телах меньшей единицы и о малой глубине формирования ПВО от единиц до сотен ангстрем. Поверхностный характер ПВО [3], обеспечивающий коэффициент отражения рентгеновских лучей от кристаллов, близкий к единице, используется на практике для создания параксиального пучка с малой расходимостью, на основе которого осуществлен рентгеновский флуоресцентный анализ с высокой чувствительностью до $10^{-10} \mathrm{~g}$ [4]. Благодаря малой глубине формирования ПВО рентгеновских лучей Кокс и Геттлиф [5] из рассчитанной теоретически калибровочной кривой определяли концентрации химических компонент в аморфных тонких пленках $\mathrm{Se}-\mathrm{Te}$. Малый пробег рентгеновских квантов в случае ПВО позволял также определять поверхностные плотности твердых тел [6], толщины поверхностных пленок алюминия в двухкомпонентной системе $\mathrm{GaAs}-\mathrm{Al}$ [7] и шероховатость поверхности твердого тела $[8,9]$. Во многих известных работах по ПВО рентгеновских лучей от поверхности твердых тел метод исследования основывался на измерениях рентгенограмм в режиме „ $\theta^{\star}$, т.е. с изменением угла скольжения $\alpha$ падающего пучка при неизменном положении счетчика рентгеновских квантов (или рентгеновской пленки) в условиях большой расходимости пучка рентгеновских лучей порядка $1^{\circ}$. В этом случае рентгенограмма ПВО рентгеновских лучей представляла собой интегральную кривую в виде квазиступенчатой функции $[1,2,10]$. Между тем в некоторых работах применение рентгеновской оптики обеспечило получение дифференциальных кривых ПВО, характеризующихся максимумами при критических углах скольжения $[7,11]$.

В настоящей работе проводится комплексное исследование рентгенограмм ПВО и дифракции рентгенов- ских лучей от поликристаллического твердого тела с последующей теоретической обработкой полученных рентгенограмм.

\section{1. Оборудование и условия эксперимента}

Эксперименты по ПВО и брэгговской дифракции рентгеновских лучей проводили на стандартной рентгеновской установке ДРОН-7 с минимально возможным шагом по углу рассеяния рентгеновских лучей $\Delta(2 \theta)=0.001^{\circ}=3.6$. Для уменьшения расходимости пучка рентгеновских лучей, падающих на образец, перед выходным окном острофокусной рентгеновской трубки с медным анодом устанавливали параболическое зеркало, обеспечивающее параксиальность падающего рентгеновского пучка с расходимостью около $0.5^{\prime}$ и полностью подавляющее спектральную линию $\mathrm{Cu} K_{\beta}$-рентгеновского излучения.

В качестве детектора рентгеновского излучения в дифрактометре ДРОН-7 используется сцинтилляционный счетчик в режиме счета отдельных рентгеновских квантов с эффективностью около 100\%. Перед детектором располагался коллиматор и горизонтальная щель Соллера. В этом случае запись рентгенограммы ПВО рентгеновских лучей в режиме ,2 $2 \theta-\theta^{\star 6}$ обеспечило получение кривой ПВО с максимумом.

На монокристалле кремния (111) предпринято методическое исследование природы максимумов, наблюдающихся на рентгенограммах ПВО рентгеновских лучей. Сравнение интегральной кривой в виде квазиступенчатой функции для кристалла кремния (рис.1, $a$ ), записанной в режиме $(\Theta)$ при неподвижном детекторе в нулевом положении и без коллиматора и щели Соллера, с соответствующей рентгенограммой для ПВО (рис. 1, $b$ ), показало качественное совпадение наибольшего наклона интегральной кривой с положением максимума на кривой ПВО. Это позволяет считать кривые ПВО с максимумами дифференциальными. 

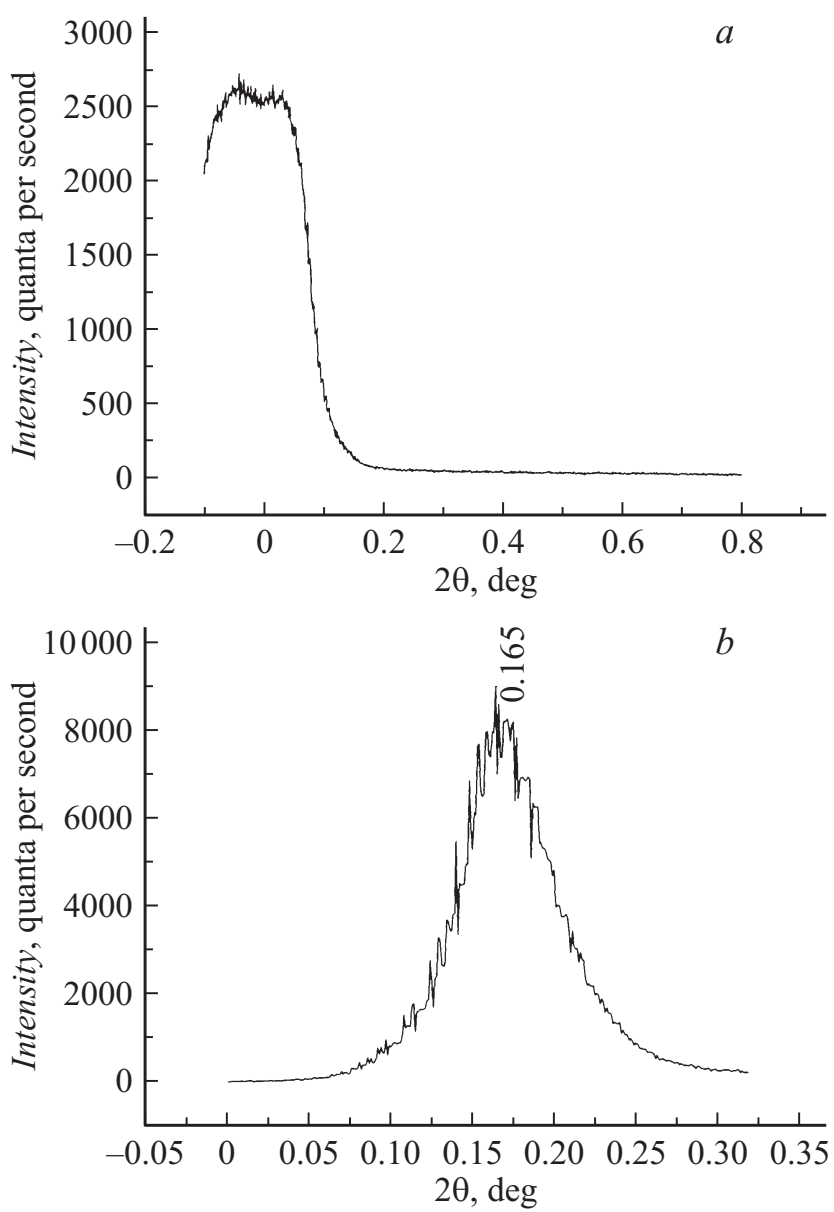

Рис. 1. Монокристалл кремния (111) с гранецентрированной решеткой: $a-$ интегральная кривая, снятая в режиме $\theta$ (без коллиматора и щели Соллера у детектора), $b$ - дифференциальная кривая, снятая в режиме $2 \theta-\theta$ (с коллиматором и щелью Соллера у детектора) с указанием угла рассеяния рентгеновских лучей $2 \theta$ в градусах.

Для исследования дифференциальных кривых ПВО на рис. 2 представлена рентгенограмма ПВО рентгеновских лучей от поверхности полированного поликристаллического тантала.

На кривой отражения наблюдаются два разрешенных максимума при разных углах скольжения $\alpha$ падающего излучения.

Таким образом, предлагаемая методика исследования ПВО рентгеновских лучей от поверхности поликристаллов обеспечивает получение дифференциальных кривых отражения в области ПВО с высоким разрешением.

\section{2. Принципы теоретической обработки кривых отражения от поверхности твердых тел}

1. Положение максимума на кривых отражения при малых (близких к нулю) углах скольжения $\alpha$ однозначно определяет показатель преломления рентгеновских лу- чей простым соотношением

$$
n=\cos \alpha
$$

Поскольку для рентгеновских лучей показатель преломления $n$ всегда меньше единицы, в кинематическом приближении выражение для n можно записать в виде:

$$
n=1-\delta
$$

где $\delta<<1$ - декремент показателя преломления.

Согласно квантовомеханической теории дисперсии [12], декремент показателя преломления рентгеновских лучей пропорционален объемной плотности рассеивающих атомов $N_{v}$ в зоне выхода $x$ рентгеновских лучей, испытавших ПВО в исследуемом образце, в соответствии с формулой:

$$
\delta=\frac{\lambda^{2} e^{2}}{2 \pi m c^{2}} N_{v} f(0)
$$

где $\lambda$ - длина волны падающего рентгеновского излучения, $e-$ заряд электрона, $m$ - масса электрона, $c$ - скорость света, $f(0)$ - атомный фактор рассеяния в направлении падающего рентгеновского излучения. Для одноатомного вещества этот атомный фактор равен порядковому номеру элемента $Z$.

В международной системе единиц СИ с учетом $f(0)=Z$ получаем практическую формулу для расчета объемной плотности рассеивающих атомов $N_{v}$ в зоне выхода рентгеновских лучей, испытавших ПВО:

$$
N_{v}=\frac{84.4594 \cdot 10^{43} \delta}{Z} \mathrm{at} / \mathrm{m}^{3} .
$$

2. В связи с тем что полное внешнее отражение рентгеновских лучей происходит при углах скольжения $\alpha$, близких к нулю, это явление представляет собой чисто поверхностный эффект с зоной выхода $x$, вычисляемой по формуле:

$$
x=\frac{\sin \alpha}{\left(\frac{\mu}{\rho}\right) \rho},
$$

где $\mu$ - линейный коэффициент поглощения рентгеновских лучей в $\mathrm{cm}^{-1}, \rho$ - плотность вещества в $\mathrm{g} / \mathrm{cm}^{3}$.

Для исследования природы максимумов кривой отражения в области ПВО рентгеновских лучей от поликристаллов наиболее информативным является метод, объединяющий измерения рентгенограмм ПВО и брэгговской дифракции рентгеновских лучей [7].

3. Согласно представлениям физики рентгеновских лучей $[12,13]$, интенсивность брэгговских рефлексов на дифрактограмме исследуемого поликристалла пропорциональна числу кристаллитов в слое толщиной Hhkl, облучаемому рентгеновскими лучами. Из известной формулы интенсивности брэгговских рефлексов от поликристаллов [12] соотношение для расчета в системе СИ числа объемных кристаллитов $N_{\mathrm{cr}}^{(h k l)}$, кристаллографические плоскости $(h k l)$ которых параллельны поверхности 


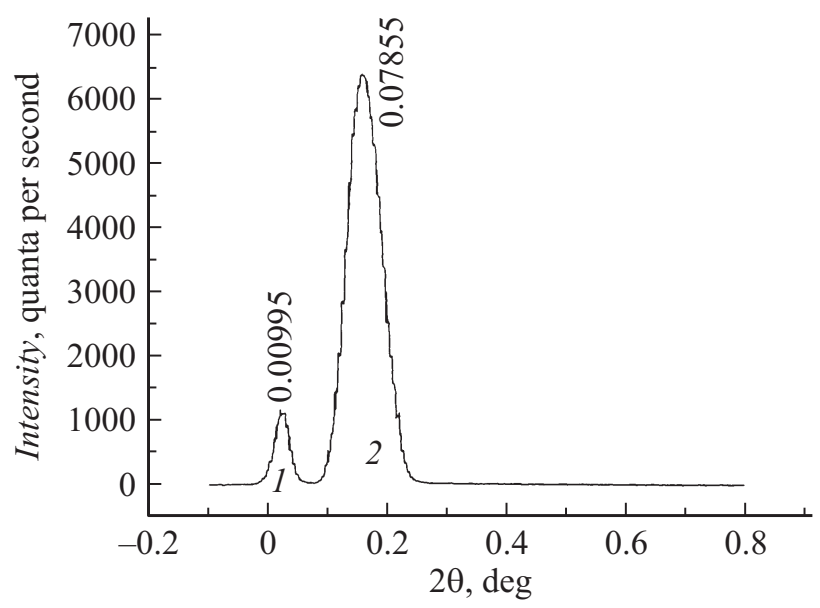

Рис. 2. Рентгенограмма полированного поликристаллического тантала в условиях полного внешнего отражения рентгеновских лучей с указанием углов скольжения $\alpha$ в градусах.

поликристалла, имеет следующий вид:

$$
N_{\mathrm{cr}}^{(h k l)}=1.59 \cdot 10^{18} I_{h k l} \frac{\sin \theta \sin 2 \theta}{f^{2} p\left(\cos ^{2} \theta+1\right)},
$$

где $I_{h k l}$ - максимальная интенсивность дифракционного пика с индексом Миллера $(h k l), \theta-$ угол дифракции от кристаллографической плоскости $(h k l), f^{2}$ - квадрат атомного фактора рассеяния рентгеновских лучей от плоскости $(h k l), p$ - фактор повторяемости кристаллографических плоскостей с индексом Миллера $(h k l)$.

Вновь подчеркнем, что ПВО рентгеновских лучей является чисто поверхностным эффектом с малой глубиной выхода. Поэтому числа кристаллитов $N_{\mathrm{cr}}^{(h k l)}$ в поверхностной зоне выхода рентгеновских лучей, испытавших ПВО, должны быть меньше чисел объемных кристаллитов в $\left(h / H_{h k l}\right)$ раз, где глубина проникновения $H_{h k l}$ дифрагированных рентгеновских лучей в твердое тело при заданном угле дифракции $\theta_{h k l}$ равна:

$$
H_{h k l}=R \sin \theta_{h k l},
$$

где $R$ - практический пробег кванта рентгеновского излучения в $\mu \mathrm{m}$. В таком случае для разных ориентаций кристаллических плоскостей числа поверхностных кристаллитов определяются из соотношений:

$$
N_{\mathrm{cr} . \mathrm{p}}^{h k l}=\left(H_{h k l}\right) N_{\mathrm{cr}}^{h k l} .
$$

\section{3. Практическое применение методики исследования ПВО рентгеновских лучей от поверхности твердых тел}

В качестве примера приведем результаты исследования ПВО рентгеновских лучей в случае полированного поликристаллического тантала, позволившие интерпретировать тонкую структуру дифференциальной кривой
Таблица 1.

\begin{tabular}{l|c|c}
\hline Величина & Пик 1 & Пик 2 \\
\hline$\alpha$, deg. & 0.00995 & 0.07855 \\
$\delta$ & $1.51 \cdot 10^{-9}$ & $9.4 \cdot 10^{-7}$ \\
$N_{v}$, at $/ \mathrm{m}^{3}$ & $1.305 \cdot 10^{34}$ & $1.088 \cdot 10^{37}$
\end{tabular}

отражения при скользящих углах падения первичного пучка. На рентгенограмме тантала в условиях ПВО (рис. 3) наблюдаются два пика при углах скольжения $\alpha_{1}=0.00995^{\circ}=0.597^{\prime}$ и $\alpha_{2}=0.07855^{\circ}=4.713^{\prime}$.

Этим углам, согласно формуле (1), соответствуют два разных показателя преломления рентгеновских лучей и вычисленные из соотношения (2) два соответствующих декремента показателя преломления.

Для тантала с $Z=73$ из соотношения (4) рабочая формула расчета объемной плотности рассеивающих атомов $N_{v}$ в зоне выхода рентгеновских лучей, испытавших ПВО, имеет следующий вид:

$$
N_{v}=1.157 \cdot 10^{43} \delta \mathrm{at} / \mathrm{m}^{3} .
$$

С помощью рабочей формулы (9) для тантала вычисляются две объемные плотности рассеивающих атомов $N_{v}$, соответствующие двум разным показателям преломления рентгеновских лучей в поликристаллическом тантале. Результаты расчетов приведены в табл. 1 .

Для выяснения природы двух разных показателей преломления рентгеновских лучей в тантале предпринято изучение дифракции рентгеновских лучей на кристаллической решетке тантала. На рис. 3 изображена дифрактограмма поликристаллического полированного тантала кубической объемно-центрированной структуры.

По известной квадратичной формуле для кубической сингонии [14] рассчитаны индексы Миллера кристаллографических плоскостей для каждого угла Брэгга

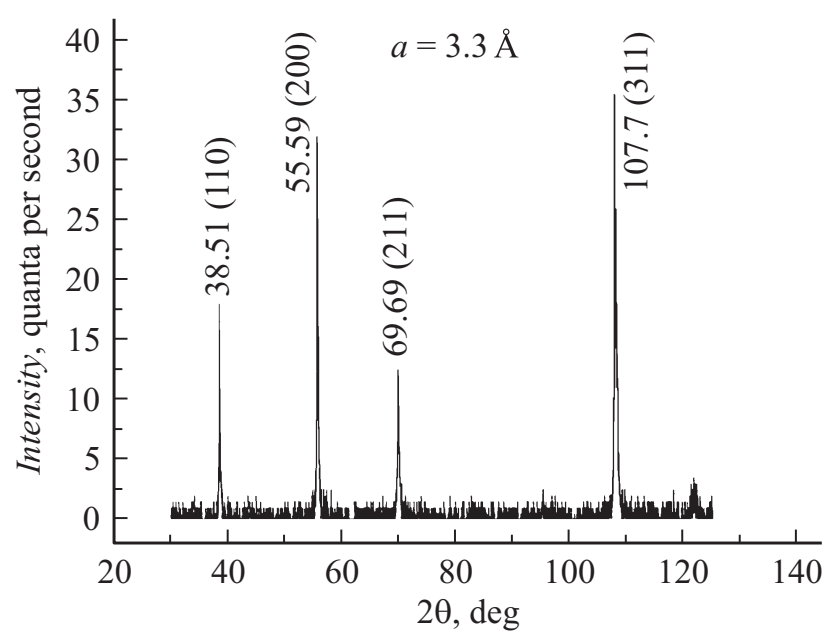

Рис. 3. Дифрактограмма полированного поликристаллического тантала с указанием углов рассеяния $2 \theta$ и индексов Миллера $(h k l)$ кристаллографических плоскостей. 
Таблица 2. Числа объемных кристаллитов $N_{\mathrm{cr}}^{(h k l)}$ в зоне выхода дифрагированных рентгеновских лучей

\begin{tabular}{c|c|c|c|c|c|c}
\hline $2 \theta^{\circ}$ & $I, \mathrm{kV} / \mathrm{s}$ & $\sin \theta / \lambda$ & $f$ & $h k l$ & $p$ & $N_{\mathrm{cr}} \cdot 10^{13}$ \\
\hline 38.5274 & 3.1 & 0.21415 & 60.4900 & 110 & 12 & 1.121982 \\
55.6190 & 61.3 & 0.30282 & 54.3649 & 200 & 6 & 118.733 \\
69.6765 & 17.9 & 0.37080 & 49.9641 & 211 & 24 & 15.2046 \\
107.7712 & 68.7 & 0.52437 & 41.5240 & 222 & 8 & 452.131
\end{tabular}

Таблица 3. Числа поверхностных кристаллитов $N_{\text {cr.p }}^{(h k l)}$ в зоне формирования ПВО рентгеновских лучей

\begin{tabular}{c|c|c|c|c|c|c|c}
\hline № & $2 \theta$ & $H \cdot 10^{-4} \mathrm{~cm}$ & $x \cdot 10^{-8} \mathrm{~cm}$ & $(x / H) \cdot 10^{-4}$ & $N_{\text {cr.p }} \cdot 10^{9}$ & $h k l$ & $d, \AA$ \\
\hline 1 & 38.5274 & 1.2273 & 6.46 & 5.2636 & 5.9057 & 110 & 2.3348 \\
2 & 55.6190 & 1.7355 & 50.9 & 29.3287 & 3482.28 & 200 & 1.6511 \\
3 & 69.6765 & 2.1251 & 6.46 & 3.0398 & 46.2189 & 211 & 1.3484 \\
4 & 107.7712 & 3.0052 & 6.46 & 2.1496 & 971.9 & 222 & 0.9535
\end{tabular}

(рис. 3) и вычислена постоянная решетки $a$, равная $3.302 \AA$.

По формуле (6) рассчитаны числа объемных кристаллитов $N_{\mathrm{cr}}^{(h k l)}$ для каждого угла Брэгга совместно с необходимыми для расчета данными (табл. 2).

В связи с тем что в отражении рентгеновских лучей в случае ПВО принимают участие кристаллиты только поверхностных слоев, для интерпретации наблюдаемых в поликристаллическом тантале различных показателей преломления рентгеновских лучей необходимо рассчитать для каждого угла Брэгга число поверхностных кристаллитов $N_{\mathrm{crs}}^{(h k l)}$, используя формулы (6), (7), и вычислить глубины выхода $x$ рентгеновских лучей, испытавших ПВО, по формуле (5).

Из таблиц Блохина [13] и Кацнельсона [15] определяются следующие значения параметров для тантала:

$$
\mu / \rho=162 \mathrm{~cm}^{2} / \mathrm{g}, \quad \rho=16.6 \mathrm{~g} / \mathrm{cm}^{3} .
$$

Подставляя эти значения для двух наблюдаемых углов скольжения $\alpha$ первичного пучка в формулу (5), получаем две соответствующие глубины выхода $x$ рентгеновских лучей, испытавших ПВО от тантала:

$$
\begin{gathered}
x_{1}=6.46 \AA=6.46 \cdot 10^{-10} \mathrm{~m} \quad \text { и } \\
x_{2}=50.9 \AA=50.9 \cdot 10^{-10} \mathrm{~m} .
\end{gathered}
$$

В табл. 3 приведены значения глубин отражения $H_{h k l}$ дифрагированных рентгеновских лучей, рассчитанных по формуле (7), величины $x$, рассчитанные по формуле (5), межплоскостные расстояния $d_{h k l}$ и с учетом табл. 2 значения $N_{\text {cr.p }}^{(h k l)}$, рассчитанные по формуле (8).

Сопоставляя отношение интенсивностей двух пиков $I_{2} / I_{1}=5.6$, присутствующих на рентгенограмме в области ПВО (рис. 3), с отношением числа поверхностных кристаллитов с кристаллографическими плоскостями (200) и (222) $N_{\text {cr.p }}^{(200)} / N_{\text {cr.p }}^{(222)}=3.8$ (табл. 3), можно сделать вывод о удовлетворительном совпадении этих отношений. Следовательно, два угла скольжения $\alpha$, наблюдаемые на рентгенограмме для ПВО от поверхности поликристаллического тантала, означают два разных показателя преломления рентгеновских лучей при отражении от двух типов кристаллитов с различными кристаллографическими плоскостями: для большего показателя преломления рентгеновских лучей в тантале $\left(n_{1}=0.99999999849\right)$ рентгеновские лучи отражаются от кристаллографической плоскости (222), параллельной поверхности образца с межплоскостным расстоянием $d_{222}=0.9535 \AA$, а для меньшего показателя преломления $\left(n_{2}=0.99999906\right)$ отражение рентгеновских лучей происходит от плоскости (200) с большим межплоскостным расстоянием $d_{200}=1.6511 \AA$. Таким образом, для ПВО рентгеновских лучей от поликристаллического тантала наблюдается обратная зависимость показателя преломления от межплоскостного расстояния. Для физического объяснения этой зависимости наряду с показателем преломления рентгеновских лучей, введем понятие о силе преломления, определяемой углом преломления $\alpha$, которая пропорциональна объемной плотности рассеивающих атомов $N_{v}$ в зоне выхода рентгеновских лучей, испытавших ПВО (табл. 1). Увеличение показателя преломления сопровождается уменьшением силы преломления и, следовательно, уменьшением объемной плотности рассеивающих атомов $N_{v}$. Как показали приведенные выше расчеты для тантала, объемная плотность рассеивающих атомов $N_{v 1}$ для большего показателя преломления на три порядка меньше объемной плотности $N_{v 2}$ для меньшего показателя преломления. Это качественно соответствует рентгенограмме для ПВО от тантала. Однако огромная разница между $N_{v 1}$ и $N_{v 2}$ связана с природой объемной плотности рассеивающих атомов. По-видимому, рассеяние рентгеновских лучей, формирующее объемную плотность атомов, в отличие от наблюдаемого ПВО происходит от всех возможных кристаллографических плоскостей в зоне выхода ПВО $x$, приводя к существенному увеличению числа рассеивающих атомов. 


\section{Заключение}

Разработанная комплексная методика измерения ПВО и дифракции рентгеновских лучей позволяет получить дифференциальные кривые ПВО от поликристаллов, соответствующие в общем случае разным показателям преломления рентгеновских лучей. Для интерпретации наблюдаемых аномалий в ПВО рентгеновских лучей от поликристаллических веществ разработаны принципы теоретической обработки кривых отражения от поверхности твердых тел. Применение экспериментальной и теоретической методик исследования ПВО в сочетании с измерениями дифракции рентгеновских лучей от поликристаллического тантала позволило объяснить различные показатели преломления в тантале полным внешним отражением рентгеновских лучей от кристаллитов с разными ориентациями. Для исследованного поликристаллического тантала установлена обратно пропорциональная зависимость показателя преломления $n$ рентгеновских лучей от межплоскостного расстояния $d$. Что касается эмпирически рассчитанных из декрементов показателя преломления объемных плотностей $N_{v}$ рассеивающих атомов, то их прямая зависимость от показателя преломления в принципе объясняет обратную зависимость $n(d)$, хотя носит лишь качественный характер.

Чтобы наблюдаемую в тантале обратную зависимость $n(d)$ считать общим законом для поликристаллов, необходимо продолжить исследования ПВО других поликристаллических веществ.

\section{Список литературы}

[1] Compton A.H. // Phil. Mag. 1923. Vol. 45. P. 1112-1120.

[2] Linnik W., Laschkarev W. // Zeitschrift fur Phys. 1926. Vol. 38. 8Heft. P. 659-670.

[3] Стоячая волна рентгена. / Сб. статей под ред. М.В. Ковальчука. 2013. М.

[4] Автореф. канд. дис. Разномазов В.М. Микроструктура и элементный анализ пленок на основе оксидов со структурой перовскита по данным рентгеновского флуоресцентного анализа с полным внешним отражением. 2010. Ростов-на-Дону.

[5] Cocks F.R., Gettlifee R. // Mater. Lett. 1985. Vol. 3. № 4. P. $133-136$.

[6] Renner O., Czech. J. // Phys. B. 1972. Vol. 22. № 10. P. $1007-$ 1016.

[7] Marra W.C., Eisenberger P., Cho A.J. // J. Appl. Phys. 1979. Vol. 50. № 11. P. 6927-6933.

[8] Sinha S.K., Sirota E.B., Garroff S., Stanley S. // Phys. Rev. B. 1988. Vol. 38. P. 2297-2302.

[9] Tolan M., Konig O., Brugemann S. // Europhys. Lett. 1992. Vol. 20. № 3. P. 223-228.

[10] Parrat L.G. // Phys. Rev. 1954. Vol. 95. № 2. P. 359-369.

[11] Touryanski A.G., Pirshin I.V. // JETP Lett. 2007. Vol. 85. № 9. P. $422-425$.
[12] Джееймс Р. Оптические принципы дифракции рентгеновских лучей. М.: ИЛ. 1950. С. 7-572.

[13] Блохин М.А. Физика рентгеновских лучей. М. Из-во Технико-теоретической литературы. 1957. С. 7-511.

[14] Миркин Л.И. Справочник по рентгеноструктурному анализу поликристаллов. М.: ФМ. 1961. С. 3-860.

[15] Кацнельсон А.А. Рассеяние рентгеновских лучей конденсированными средами. М.: Из-во МГУ, 1991. С. 1-96. 